\title{
Characteristics and Lytic Activity of Phage-Derived Peptidoglycan Hydrolase, LysSAP8, as a Potent Alternative Biocontrol Agent for Staphylococcus aureus ${ }^{\text {S }}$
}

\author{
Jun-Hyeok Yu ${ }^{1}$, Jeong-A Lim ${ }^{2}$, Hyun-Joo Chang ${ }^{2 *}$, and Jong-Hyun Park ${ }^{1 *}$ \\ ${ }^{1}$ Department of Food Science and Biotechnology, College of BioNano Technology, Gachon University, Seongnam 13120, Republic of Korea \\ ${ }^{2}$ Research Group of Consumer Safety, Korea Food Research Institute, Wanju-gun 55365, Republic of Korea
}

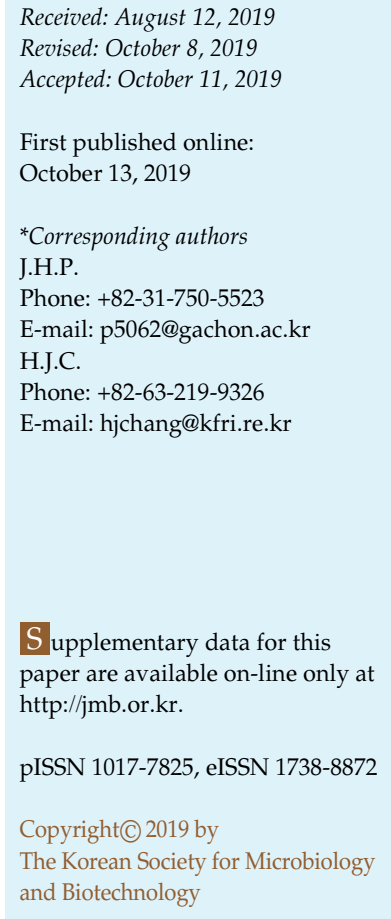

S upplementary data for this paper are available on-line only at http://jmb.or.kr.

pISSN 1017-7825, eISSN 1738-8872

Copyright(C) 2019 by

The Korean Society for Microbiology and Biotechnology

\begin{abstract}
Outbreaks of staphylococcal food poisoning (SFP) causing serious human diseases and economic losses have been reported globally. Furthermore, the spread of Staphylococcus aureus with increased resistance to multiple antimicrobial agents has become a major concern in the food industries and medicine. Here, we isolated an endolysin LysSAP8, as one of the peptidoglycan hydrolases, derived from the bacteriophage SAP8 infecting S. aureus. This endolysin was tagged with a $6 \times$ His at the C-terminal of the target protein and purified using affinity chromatography. LysSAP8 demonstrated lytic activity against a broad spectrum of bacteria, which included a majority of the staphylococcal strains tested in this study as well as the methicillin-resistant $S$. aureus (MRSA); however, no such activity was observed against other gram-positive or gram-negative bacteria. Additionally, LysSAP8 could maintain bactericidal activity until $0.1 \mathrm{nM}$ working concentration and after heat treatment at $37^{\circ} \mathrm{C}$ for $30 \mathrm{~min}$. The ability of LysSAP8 to lyse cells under varying conditions of temperature $\left(4-43^{\circ} \mathrm{C}\right)$, $\mathrm{pH}(3-9)$, and $\mathrm{NaCl}$ concentrations $(0-1,000 \mathrm{mM})$, and divalent metal ions $\left(\mathrm{Ca}^{2+}, \mathrm{Co}^{2+}, \mathrm{Cu}^{2+}\right.$, $\mathrm{Mg}^{2+}, \mathrm{Mn}^{2+}, \mathrm{Hg}^{2+}$, and $\mathrm{Zn}^{2+}$ ) was examined. At the optimized condition, LysSAP8 could disrupt approximately $3.46 \log \mathrm{CFU} / \mathrm{ml}$ of the planktonic cells in their exponential phase of growth within $30 \mathrm{~min}$. In this study, we have suggested that LysSAP8 could be a potent alternative as a biocontrol agent that can be used to combat MRSA.
\end{abstract}

Keywords: Staphylococcus aureus, bacteriophage, endolysin, MRSA

\section{Introduction}

Staphylococcus aureus is a gram-positive, facultative, anaerobic bacterium commonly found in households and communities such as schools, farms, and workplaces, and on the human skin [1]. These bacteria possess multiple virulence factors that cause the rapid onset of various symptoms of foodborne diseases such as nausea and violent vomiting with or without diarrhea [2]. Many outbreaks of food poisoning caused by $S$. aureus have been reported globally, including in the Republic of Korea, Europe and the United States [3-5]. Unfortunately, S. aureus not only causes economic losses in the food industry, but also contributes to the spread of multidrug-resistant (MDR) infections, and strains of methicillin-resistant Staphylococcus aureus (MRSA) are the common drug-resistant types that have been identified [6]. Although most of the MRSA strains are associated with infections of the skin and soft tissues, approximately 5-10\% cause life-threatening conditions like septicemia and necrotizing pneumonia [1].

The emergence of multidrug-resistant bacteria has led to the development of therapies employing bacteriophages as alternative options to treat these infections [7, 8]. The applications of bacteriophages in clinical therapy, displaying, food safety, and decontamination have been researched globally [9]. Although the use of phages has 
seen a number of achievements, several concerns regarding their safety, efficacy, and development of bacterial resistance towards phages still exist [10]. Consequently, there has been an increased focus on the application of the endolysin derived from bacteriophage [11-13]. Endolysins are responsible for the enzymatic degradation of the host peptidoglycan (PG) resulting in the release of progeny virions and death of the host cell [13]. In several studies, the exogenous application of endolysin as a therapeutic agent has enabled the rapid and successful control of target pathogens both in vitro and in vivo [14-16]. Furthermore, synthetic approaches by chimeric modification of endolysins have successfully enhanced their lytic activities [17]. LysK, as the most well-studied Staphylococcus phage endolysin, harbors an N-terminal cysteine/histidine-dependent amidohydrolase/peptidase (CHAP) domain, a central amidase domain, and a C-terminal SH3b cell wall-binding domain [18-21]. LysK-like endolysins have been studied in a broad range of areas such as the food industry, therapy, and protein crystallization [20,22, 23]. Especially, SAL200 and LysGH15 as endolysins against Staphylococcus species exhibited tremendous lysis activities and synergic availabilities against $S$. aureus including MRSA [16, 24]. Nevertheless, only a few LysK-like endolysins have been isolated and characterized, though their potential as available agents for application is unclear.

We have characterized an endolysin designated LysSAP8 as a newly isolated endolysin from $S$. aureus-specific phage SAP8. LysSAP8 is a LysK-like lysin composed of two lytic domains and a single cell wall-binding domain. Many factors that affected the lytic activity of LysSAP8 were examined and its host spectrum was confirmed. The current data validate the potential of LysSAP8 as a promising alternative agent for the biocontrol of S. aureus.

\section{Materials and Methods}

\section{Bacterial Strains and Culture Conditions}

In total, 116 strains were used (Table S1) for the study on the lytic spectrum of LysSAP8. Among the 75 isolates of S. aureus that were used, 32 clinical isolates were donated by Severance Hospital (Korea) and the remaining 43 were isolated from food samples between 2005 and 2006 in our laboratory. Type strains were obtained from four microbiology collections (KCTC, KCCM, ATCC, and NCCP) and wild-type strains were donated by the laboratory of professor Young-Seo Park (Gachon University, Korea). All bacterial strains were routinely cultured overnight in Luria-Bertani (LB, Difco Co., USA) broth at $37^{\circ} \mathrm{C}$ under conditions of shaking, or in $\mathrm{LB}$ containing $1.5 \%$ agar and incubated at $37^{\circ} \mathrm{C}$.

\section{Plaque Assay}

In 2013, S. aureus KCCM 12103 was used to isolate SAP8 using conventional methods [25]. To confirm the presence of phage plaques, phage lysate of SAP8 was serially diluted in SM buffer $\left(5.8 \mathrm{~g} / 1 \mathrm{NaCl}, 2 \mathrm{~g} / 1 \mathrm{MgSO}_{4}, 40 \mathrm{ml} / 1\right.$ of $1 \mathrm{M}$ Tris-HCl, $0.1 \mathrm{~g} / 1$ gelatin, $\mathrm{pH} 7.5)$, and overlaid with LB soft agar ( $0.6 \%$ agar) on cells of the host bacterium S. aureus KCCM 12103 using the agar layer method. The plate overlaid with agar was incubated overnight at $37^{\circ} \mathrm{C}$ and the plaque was measured.

\section{Electron Microscopy}

The phage lysate was purified using a modified polyethylene glycol precipitation method [26]. Purified phage solution was deposited onto formvar-carbon 200 mesh TH copper grids (Ted Pella, Inc., USA) stained with $2 \%$ uranyl acetate. The morphology of SAP8 was examined using a transmission electron microscope (Tecnai G2 F30 S-TWIN, FEI, USA).

\section{Complete Genome Sequencing}

Genomic DNA of the phage was extracted using the Genomic DNA Extraction Kit (Qiagen Tissue and Blood Kits, USA), according to the manufacturer's instructions. Purified whole genome of the phage was sequenced using the GS Junior Sequencing system (Roche, USA), and its open reading frames (ORFs) were predicted using Glimmer version 3.02 by Chunlab Inc. (Korea).

\section{Accession Number}

The genome of SAP8 was submitted to GenBank under accession number MK801680.

\section{Genomic Analysis of SAP8}

The predicted ORFs were annotated using Blastp based on the e-value $<1 \mathrm{E}-05$, and classified into six groups based on their functions: packaging, structure, host lysis, DNA manipulation, DNA regulation, and additional function. The $\mathrm{G}+\mathrm{C}$ content was predicted using the DNA/RNA GC content calculator from ENDMEMO (http://www.endme mo.com/bio/gc.php), and the tRNAscan-SE 1.21 (The Lowe Lab, University of California Santa Cruz, USA) was used to search for the tRNA $[27,28]$.

\section{Bioinformatic Analysis of LysSAP8}

The modular organization of the bacteriophage endolysin was predicted using information from the NCBI database (http:// blast.ncbi.nlm.nih.gov/Blast.cgi) and Blastp [29]. For phylogenetic analysis, 24 sequences of endolysins, including that of LysSAP8 derived from the bacteriophages infecting $S$. aureus, were aligned using ClustalW [30]. These endolysin alignments were constructed into a phylogenetic tree by the neighbor-joining method with 1000 bootstrap replicates using MEGA 7 (MEGA) [31]. The NCBI database was accessed to identify all endolysin sequences.

\section{Protein Expression and Purification}

For purification of the endolysin, the gene encoding LysSAP8 
was amplified by PCR using the primers containing $5^{\prime} \mathrm{NdeI}$ and $3^{\prime}$ Xhol restriction sites. Based on the putative endolysin gene of SAP8, the primers SAP8_F \#5 (5'-GGAATTCCATATGTTAAT GACAAAA-AATCAA-3') and SAP8_R \#4 (5'-CCGCTCGAGAAT CGTGCTAAA-3') were designed. The amplified PCR product was digested with NdeI and XhoI, and ligated into the pET23a vector containing a C-terminal $6 \times$ histidine. The recombinant vector, pET23a_LysSAP8, was transformed into competent Escherichia coli Rosetta (DE3) cells containing pRARE as a codon supplement [32].

The transformant was grown until this reached an $\mathrm{O}^{\mathrm{D}} \mathrm{D}_{600}$ of $0.7-$ 0.8 in LB broth supplemented with ampicillin (final conc. $50 \mu \mathrm{g} / \mathrm{ml}$ ) and chloramphenicol (final conc. $12.5 \mu \mathrm{g} / \mathrm{ml}$ ), and induced by the addition of $1 \mathrm{mM}$ isopropyl $\beta$-D-1-thiogalactopyranoside (IPTG) followed by incubation at $18^{\circ} \mathrm{C}$ for $18 \mathrm{~h}$ with shaking $[33,34]$. The induced E. coli were harvested by centrifugation $(4,000 \times g$ for $10 \mathrm{~min})$, resuspended in lysis buffer $(50 \mathrm{mM}$ Tris- $\mathrm{HCl} / 500 \mathrm{mM}$ $\mathrm{NaCl} / 10 \mathrm{mM}$ imidazole, $\mathrm{pH} 8.0$ ), and sonicated on ice for $30 \mathrm{~min}$ (5/2 s pulse on/off, Amp 40\%) using a model VCX130 device (Vibra-Cell, USA). The debris of lysate was removed by centrifugation $(25,000 \times g$ for $10 \mathrm{~min})$ to obtain a soluble form of the endolysin, which was purified by affinity chromatography using an Ni-NTA Superflow resin (Qiagen), according to the manufacturer's instructions. Sodium dodecyl sulfate-polyacrylamide gel electrophoresis (SDS-PAGE) was conducted to identify the purified endolysin and its concentration was determined using the Bradford reagent (Bio-Rad Laboratories, USA) according to the manufacturer's instructions.

\section{Characterization of LysSAP8}

The minimal bactericidal concentration (MBC) of LysSAP8 was determined by serially diluting the endolysin [35]. S. aureus KCCM 12103 as a target bacteria of the endolysin was cultured to its exponential phase $\left(>10^{8} \mathrm{CFU} / \mathrm{ml}\right)$ and washed twice with the reaction buffer ( $50 \mathrm{mM}$ Tris- $\mathrm{HCl} / 500 \mathrm{mM} \mathrm{NaCl}, \mathrm{pH}$ 8.0) by centrifugation $(4,000 \times g$ for $10 \mathrm{~min})$. LysSAP8 was serially diluted and inoculated into the washed $S$. aureus (final conc. 1,000, 100, 10, $1,0.1,0.01 \mathrm{nM}$ ) culture. After incubation at $30^{\circ} \mathrm{C}$ for $30 \mathrm{~min}$, the O. $D_{600}$ value was determined. The MBC was defined as the lowest concentration generating turbidity reduction of the target bacteria at $30^{\circ} \mathrm{C}$ for $30 \mathrm{~min}$.

The range of lysis activity of LysSAP8 was tested against 116 bacterial strains including MRSA by the spot assay [24]. LysSAP8 was spotted onto the bacterial lawn, the cells of which were in their exponential phase of growth and dried at room temperature for $30 \mathrm{~min}$. The spotted plates were incubated overnight at $37^{\circ} \mathrm{C}$ and observed for the formation of clear zones.

To assess the thermal stability of LysSAP8, LysSAP8 was preincubated at high temperatures $\left(30^{\circ} \mathrm{C}, 37^{\circ} \mathrm{C}, 40^{\circ} \mathrm{C}, 45^{\circ} \mathrm{C}, 50^{\circ} \mathrm{C}\right.$, $60^{\circ} \mathrm{C}, 70^{\circ} \mathrm{C}$, and $80^{\circ} \mathrm{C}$ ) for $30 \mathrm{~min}$ [36]. Untreated endolysin served as the control. The treated LysSAP8 was inoculated onto the cell preparations. After incubation at $30^{\circ} \mathrm{C}$ for $30 \mathrm{~min}$, its residual activity was measured by determining the O.D $D_{600}$ value.
The effects of temperature, $\mathrm{pH}, \mathrm{NaCl}$ concentrations and the presence of divalent metal ions on the antimicrobial activity of LysSAP8 were assessed by a turbidity reduction assay [20, 37, 38]. To test the susceptibility of LysSAP8 at various factors, the endolysin was inoculated into the cell preparation (final conc. $1 \mu \mathrm{M})$, which was then incubated for $30 \mathrm{~min}$ with the following conditions: temperature $\left(4^{\circ} \mathrm{C}, 15^{\circ} \mathrm{C}, 25^{\circ} \mathrm{C}, 30^{\circ} \mathrm{C}, 37^{\circ} \mathrm{C}\right.$, and $\left.43^{\circ} \mathrm{C}\right)$, $\mathrm{pH}(50 \mathrm{mM}$ citrate buffer $\mathrm{pH} 3-5,50 \mathrm{mM}$ imidazole- $\mathrm{HCl}$ buffer $\mathrm{pH}$, and $50 \mathrm{mM}$ tris- $\mathrm{HCl}$ buffer $\mathrm{pH} 7-9), \mathrm{NaCl}(0,500,750$, and $1,000 \mathrm{mM})$, and divalent metal ions (1 mM: $\mathrm{Ca}^{2+}, \mathrm{Co}^{2+}, \mathrm{Cu}^{2+}, \mathrm{Mg}^{2+}$, $\mathrm{Mn}^{2+}, \mathrm{Hg}^{2+}$, and $\mathrm{Zn}^{2+}$, and EDTA for control). After incubation, the O. $D_{600}$ value was determined.

A viable cell counting assay was conducted to assess the lysis capability of LysSAP8 under the optimized condition. S. aureus KCCM 12103 was cultured to its exponential phase $\left(>10^{8} \mathrm{CFU} / \mathrm{ml}\right)$ and washed twice with the optimized buffer (Tris- $\mathrm{HCl} / 500 \mathrm{mM}$, $\mathrm{NaCl} / 1 \mathrm{mM} \mathrm{CaCl}_{2}, \mathrm{pH} 8.0$ ) by centrifugation $(4,000 \times g$ for $10 \mathrm{~min}$ ). LysSAP8 was inoculated into the washed cell suspension (final conc. $1 \mu \mathrm{M}$ ) and incubated at $30^{\circ} \mathrm{C}$ for $30 \mathrm{~min}$. It was then diluted serially and spread on LB medium containing $1.5 \%$ agar. After overnight incubation at $37^{\circ} \mathrm{C}$, individual colonies were counted.

\section{Statistical Analysis}

Statistically significant differences were evaluated using an unpaired one-tailed $t$-test for three independent experiments. $p$ values less than 0.01 were considered to be statistically significant.

\section{Results and Discussion}

\section{Morphological Features of SAP8}

The bacteriophage SAP8 infecting S. aureus was isolated from feces. The morphological analysis of SAP8 by transmission electron microscopy revealed that SAP8 has a long non-contractile tail approximately $300 \mathrm{~nm}$ in length, exhibiting typical characteristics representative of the Siphoviridae family with the adopted elongated head (Fig. 1).

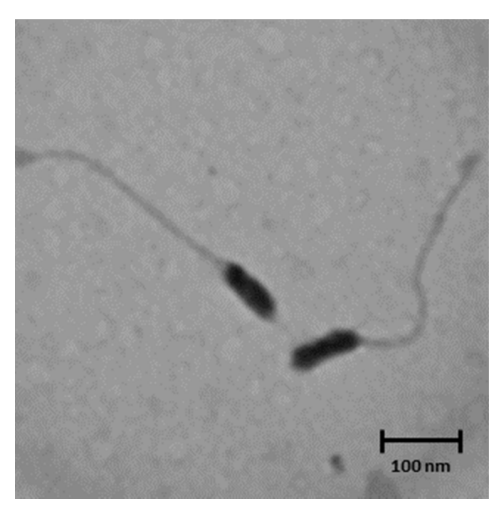

Fig. 1. Morphology of SAP8. A scale bar is presented at the bottom of the picture. 
Table 1. Genomic features of the bacteriophage SAP8 infecting S. aureus.

\begin{tabular}{lc}
\hline \multicolumn{1}{c}{ Features } & SAP8 \\
\hline Genomic size (bp) & 45,533 \\
No. ORFs & 64 \\
No. hypothetical genes & 31 \\
Encoding region (\%) & 92.77 \\
G+C content (\%) & 33.41 \\
No. tRNA & 0 \\
\hline
\end{tabular}

\section{Genomic Features of SAP8}

The genomic features of SAP8 were analyzed based on its complete sequence data (Table 1). The genome of SAP8 was $45,553 \mathrm{bp}$ in size and was composed of 64 ORFs without tRNA. The G+C content of SAP8 was approximately $33 \%$. The annotated genes from SAP8 were categorized into six functional groups and arranged (Fig. 2). Gene clustering in each functional group was found. Phage SAP8 harbored terminase and portal protein genes as essential packaging genes in many phages, promoting the translocation of viral genome into their capsid proteins. Also, phage SAP8 harbored eight structural genes, including head, tape measure protein, peptidase (tail lysin), and tail genes. In the DNA manipulation group, site-specific integrase present in SAP8 indicated that it possesses the ability to lysogenize host cells. For the host lysis, CHAP domain-containing protein as an endolysin of SAP8 (LysSAP8) and holin were located beside the site-specific integrase gene. In addition, a total of 13 genes for DNA regulation such as nuclease were encoded in the SAP8 genome.

\section{Molecular Features of LysSAP8}

The proteomic size and functional domains of LysSAP8 were predicted by bioinformatic analysis (Fig. 3A). The LysSAP8 proteome was determined to be 484 amino acids long and approximately $53 \mathrm{kDa}$ in molecular weight. LysSAP8 was composed of an N-terminal CHAP, amidase3 in the middle, and SH3b at the C-terminal end. CHAP and amidase-3, the proteins responsible for enzymatic

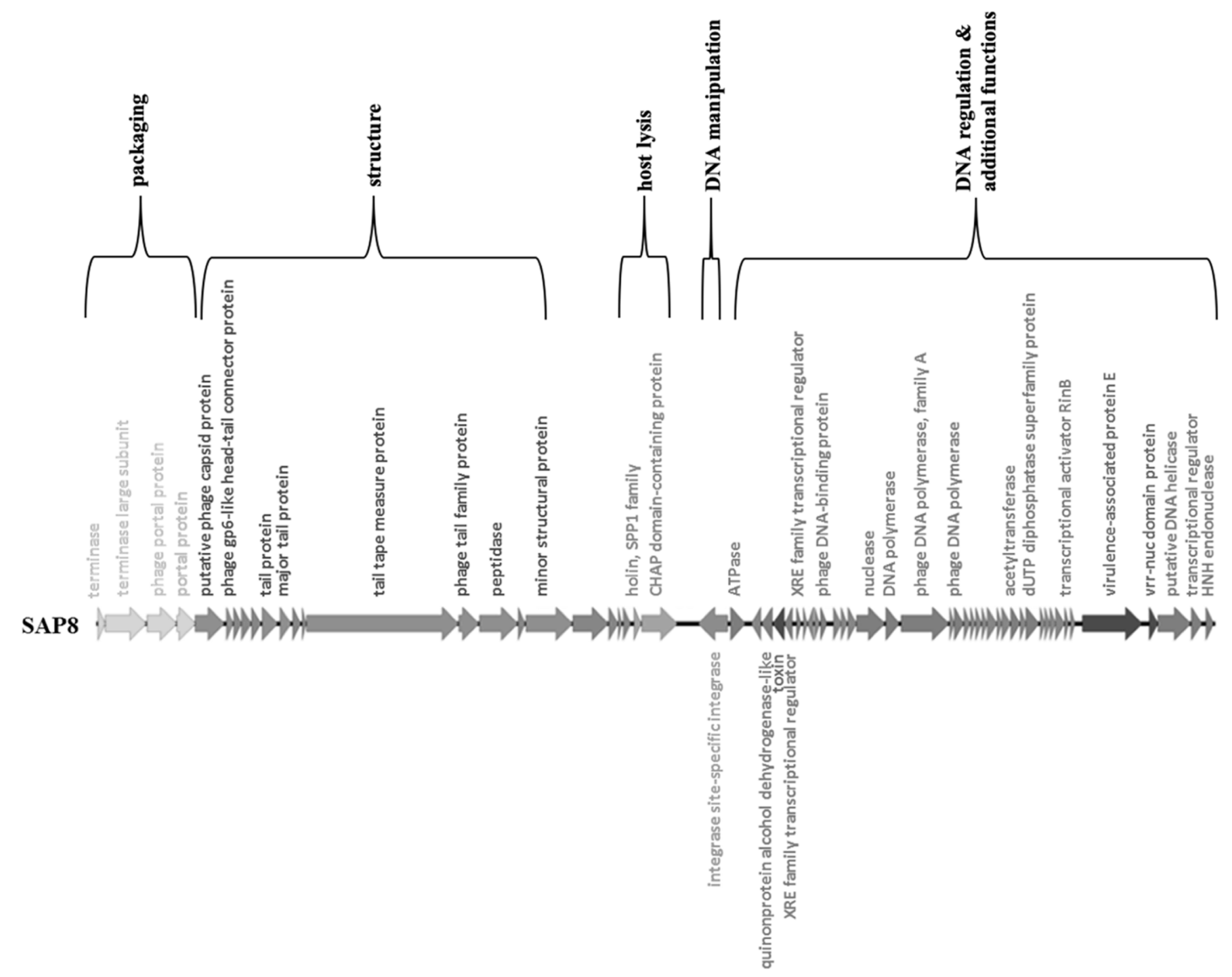

Fig. 2. Genetic organization of SAP8.

Genetic organization of SAP8. Predicted open reading frames are denoted by arrows. 

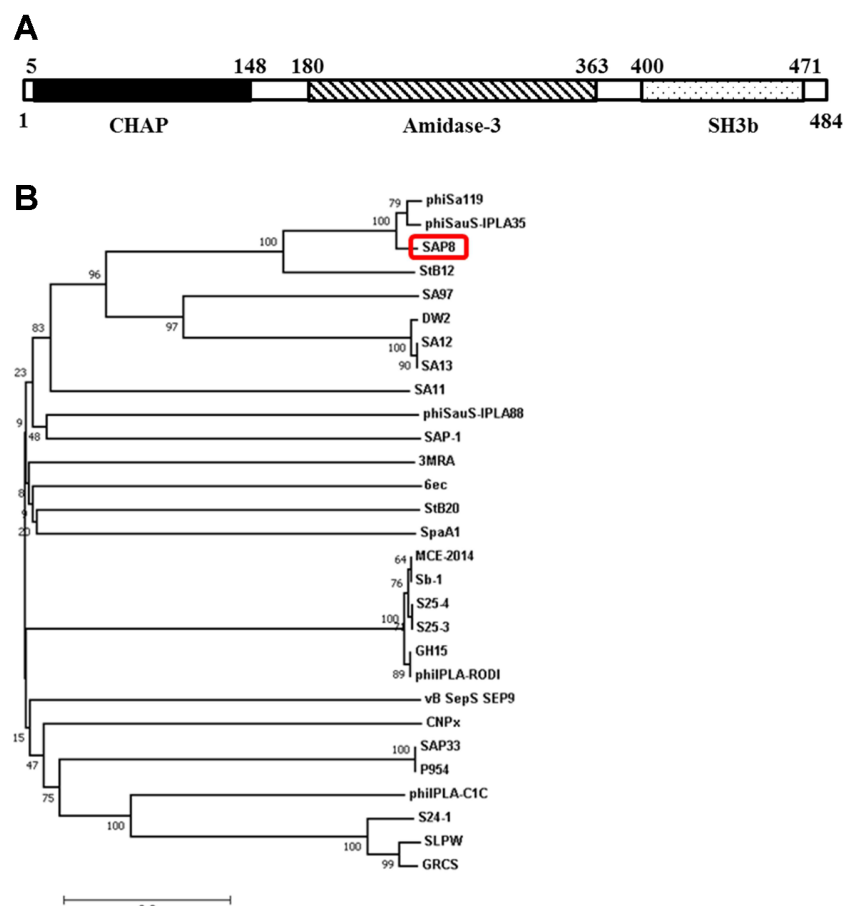

Fig. 3. (A) Modular organization of LysSAP8. (B) Phylogenetic tree for endolysins derived from bacteriophages infecting S. aureus including LysSAP8.

Black box: histidine-dependent amidohydrolase/peptidase (CHAP); Diagonal stripes: amidase-3; Black dots: SH3b. Unit: amino acid sequence.

degradation of peptidoglycan, were identified as enzymatically active domains (EADs) and $\mathrm{SH} 3 \mathrm{~b}$ was a typical cell wall-binding domain (CBD). Thus, it was determined that LysSAP8 was composed of two EADs and one CBD. These results showed that LysSAP8, as a LysK-like lysin, belongs to the type IV category, based on the grouping of staphylococcal endolysins [37]. Moreover, similar to LysK, LysSAP8 was determined to be approximately $53 \mathrm{kDa}$ in molecular weight and composed of three domains [21, 22].

In the phylogenetic analysis, the taxonomical features of LysSAP8 were analyzed by comparing with those of other bacteriophage endolysins for $S$. aureus that were available in the NCBI database (Fig. 3B). The phylogenetic tree revealed that all endolysins analyzed here could be divided into two groups. Among each group, the characteristics of SAP8 were very similar to those of phiSA119 and phiSauS_IPLA35.

\section{Host Spectrum, MBC, and Thermal Stability of LysSAP8}

LysSAP8 overexpressed in E. coli was partially purified using nickel-chelating affinity chromatography. The

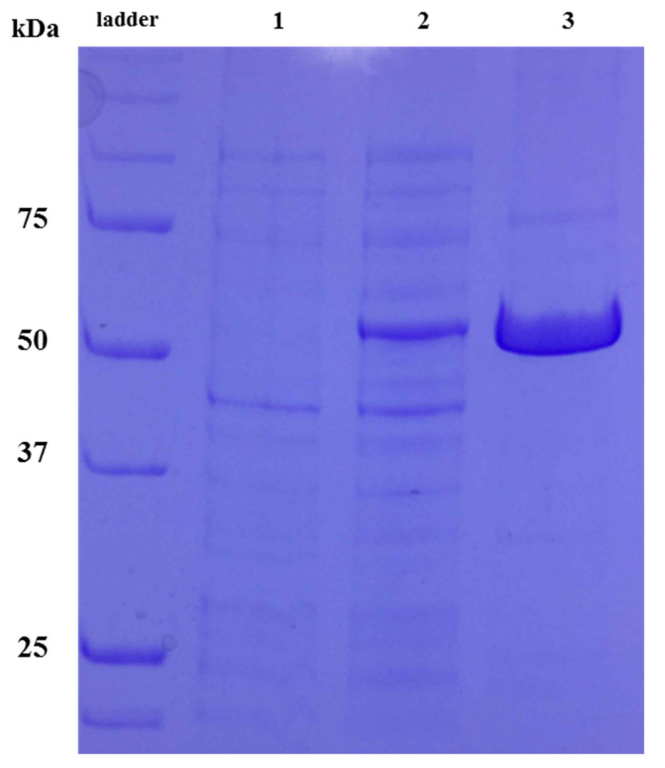

Fig. 4. SDS-PAGE analysis for expression and purification of LysSAP8 (55 kDa).

Lane 1: total lysate of IPTG-induced E. coli harboring the backbone plasmid; Lane 2: total lysate of IPTG-induced E. coli harboring the recombinant plasmid; Lane 3: partially purified endolysin.

molecular weight of LysSAP8 fused with histidine tag was found to be around $55 \mathrm{kDa}$. SDS-PAGE of the expressed bacterial fraction showed the presence of a dense protein band of the target size (Fig. 4).

Although phage SAP8 had relatively narrow host spectrum (15/75), LysSAP8 which was derived from phage SAP8 demonstrated lytic activity against a broad spectrum of the tested staphylococcal strains (Table S1). Among the $75 \mathrm{~S}$. aureus isolates including MRSA, 73 strains showed susceptibilities to LysSAP8. Additionally, lysis activity of LysSAP8 against most of the other staphylococcal species (S. epidermidis, S. hominis, S. sciuri, S. warneri, S. xylosus) was also observed except for S. condiment PS10-3, S. warneri CCBK901, S. epidermidis KCCM 35494 and 40416. However, LysSAP8 killed neither the other gram-positive (Bacillus, Enterococccus, Lactobacillus, Listeria, Streptococcus) nor gramnegative (Escherichia, Enterobacter, Klebsiella, Salmonella, Vibrio) strains. These results presented its advantages as a biocontrol agent that could be employed in the food industry and could enable targeting of specific pathogens without causing death of the commensal microflora. Interestingly, phage SAP8 could not infect any of the tested MRSA which were susceptible to LysSAP8. These results suggested that antibiotic resistant-bacteria might be susceptible to endolysin LysSAP8, even if they were 


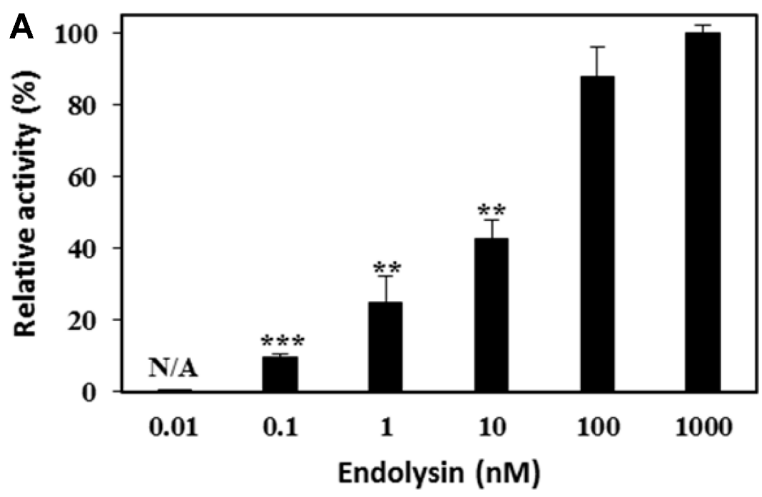

B

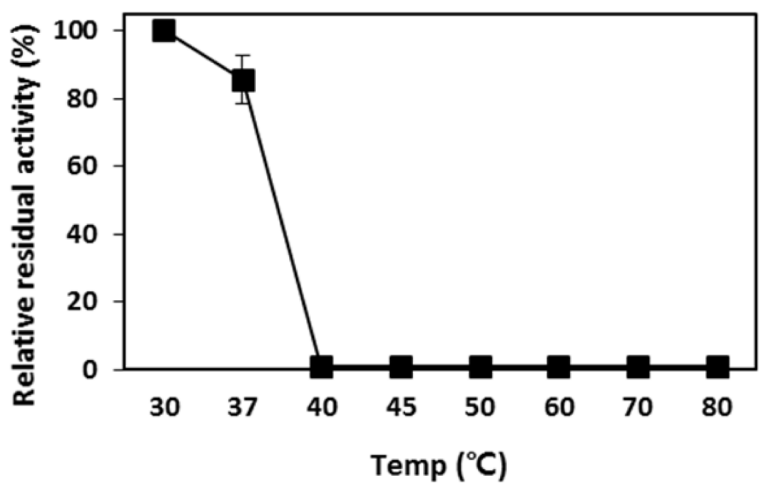

Fig. 5. Minimal inhibitory concentration (MIC) and protein thermal shift assays conducted on LysSAP8.

(A) Minimum concentration to kill the target bacteria, (B) Stability upon high temperature treatment for $30 \mathrm{~min}$. The relative activities were calculated based on the highest turbidity reduction rate on each experiment. The data are presented as means of the standard deviations of the triplicate assays. ${ }^{*} p<0.01 ;{ }^{* *} p<0.001 ;{ }^{* * *} p<0.0001$; N/A: not available.

insensitive to phage SAP8 which was the source of LysSAP8.

To determine the MBC of LysSAP8, it was serially diluted (final conc. 1000, 100, 10, 1, 0.1, $0.01 \mathrm{nM}$ ) and inoculated with S. aureus KCCM 12103 as the target bacteria (Fig. 5A). LysSAP8 showed lytic activity depending on its concentration, and the highest activity that was not significantly different with those at $1,000 \mathrm{nM}$ was observed at $100 \mathrm{nM}$. The lowest concentration at which LysSAP8 demonstrated bactericidal activity was $0.1 \mathrm{nM}$. This suggested that, from the viewpoint of cost efficiency, LysSAP8 might be the preferred bactericidal agent.

The stability of LysSAP8 under conditions of high temperature was determined (Fig. 5B). After heat treatment for $30 \mathrm{~min}$, the residual enzymatic activity of LysSAP8 remained unchanged till $37^{\circ} \mathrm{C}$. However, the residual enzymatic activity of LysSAP8 was lost with unrecoverable inactivation by following treatment above $40^{\circ} \mathrm{C}$ for $30 \mathrm{~min}$.
These results showed a broad host spectrum of LysSAP8 against most of the Staphylococcus species tested in this study, suggesting their high-efficiency as biocontrol agents. Especially, a low MBC of LysSAP8 $(0.1 \mathrm{nM} \fallingdotseq 5.3 \mu \mathrm{g} / \mathrm{ml})$ revealed a highly bactericidal effect against $S$. aureus in logarithmic growth phase, comparing those of endolysin LysK $(1.4 \mu \mathrm{M})$ and P28 $(125 \mu \mathrm{g} / \mathrm{ml})[36,39]$. However, endolysin LysSAP8 had poor thermal stability as one of its drawbacks. Although LysSAP8 was less thermo-stable than other endolysins such as PlySs2 and LysSA11 [37, 40], several studies presented possible methods to improve thermal-stability of endolysin by using reverse micelles entrapping proteins or in combination with multiple thermo-stabilizing amino acid mutations [13, 41].

Effects of Temperature, $\mathrm{pH}, \mathrm{NaCl}$, and Divalent Metal Ions on Antibacterial Activity of LysSAP8

The antimicrobial activity of LysSAP8 was assessed using the turbidity reduction assay under the following conditions: temperature $\left(4-43^{\circ} \mathrm{C}\right), \mathrm{pH}(3-9), \mathrm{NaCl}$ concentration $(0-$ $1,000 \mathrm{mM}$ ), and $1 \mathrm{mM}$ concentration of various divalent metal ions $\left(\mathrm{Ca}^{2+}, \mathrm{Co}^{2+}, \mathrm{Cu}^{2+}, \mathrm{Mg}^{2+}, \mathrm{Mn}^{2+}, \mathrm{Hg}^{2+}\right.$, and $\left.\mathrm{Zn}^{2+}\right)$.

It was found that LysSAP8 was completely active between temperatures of $15^{\circ} \mathrm{C}$ and $30^{\circ} \mathrm{C}$ (Fig. 6A). However, at temperatures below $4^{\circ} \mathrm{C}$, the lytic activity was reduced to $58 \%$ and at temperatures over $37^{\circ} \mathrm{C}$, nearly complete loss of its activity was observed. Interestingly, as shown in Fig. 5B, although the enzymatic activity of LysSAP8 was recoverable when it was pre-incubated at $37^{\circ} \mathrm{C}$, the lysis activity of LysSAP8 was drastically low at this temperature.

On the buffers adjusted to $\mathrm{pH}$ values from 3 to 9, LysSAP8 demonstrated variations in lytic activity (Fig. 6B). The optimum pH of LysSAP8 was 7 to 8, but its activity was significantly decreased to less than $50 \%$ in the buffer adjusted to $\mathrm{pH}$ 6. Additionally, its lytic activity was almost lost in buffers at $\mathrm{pH}$ less than 5. Furthermore, at $\mathrm{pH} 9$, the lytic activity of LysSAP8 was found to decrease.

In the experiment conducted to assess the effects of different concentrations of $\mathrm{NaCl}$ on the endolysin, lytic activity of LysSAP8 varied significantly with change in $\mathrm{NaCl}$ concentrations (Fig. 6C). In the absence of $\mathrm{NaCl}$, the efficacy of LysSAP8 for lysis was approximately $50 \%$ of that in buffer supplemented with $500 \mathrm{mM} \mathrm{NaCl}$, which was considered the optimum $\mathrm{NaCl}$ concentration. Moreover, its activity was found to decrease drastically in buffer containing $750 \mathrm{mM} \mathrm{NaCl}$ and was almost inactivated in $1,000 \mathrm{mM} \mathrm{NaCl}$ buffer.

The effects of divalent metal ions on the lysis activity were determined by testing LysSAP8 in the presence or 

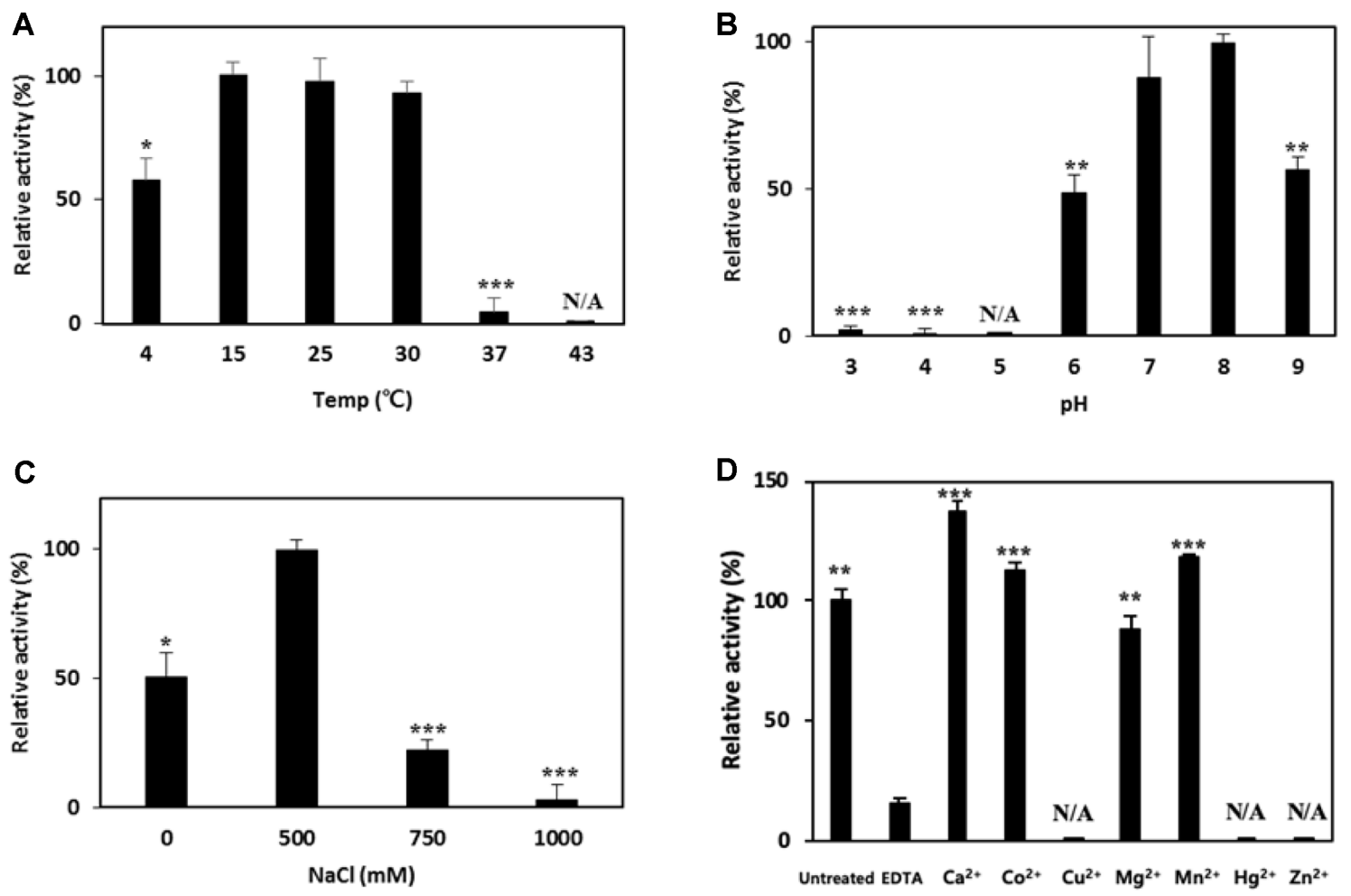

Fig. 6. Effects of temperature, $\mathrm{pH}, \mathrm{NaCl}$, and divalent metal ion on lytic activity of LysSAP8.

(A) Temperature (B) $\mathrm{pH}$ (C) $\mathrm{NaCl}$ (D) divalent metal ions. The relative activities of (A), (B), and (C) were calculated based on the highest turbidity reduction rate on each experiment, and the relative activities of $(\mathbf{D})$ were calculated based on the turbidity reduction rate of the untreated control. The data are presented as means with standard deviations of triplicate assays. ${ }^{*} p<0.01$; ${ }^{* *} p<0.001 ;{ }^{* * *} p<0.0001$; N/A: not available.

absence of the ions (Fig. 6D). Lytic activity of LysSAP8 was found to decrease significantly upon treatment with EDTA suggesting that it might require metal ions for high efficacy of lysis activity. Furthermore, treatments with $\mathrm{Cu}^{2+}, \mathrm{Hg}^{2+}$,

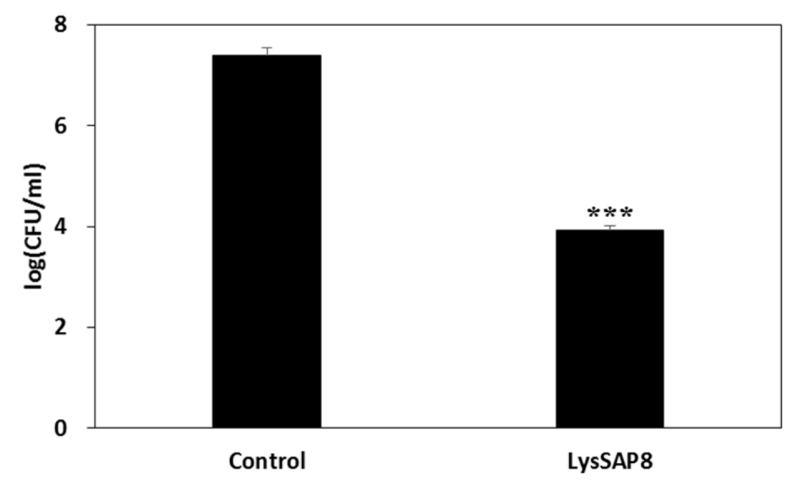

Fig. 7. Lysis capability of LysSAP8 under the optimized condition.

Lysis capability of LysSAP8 under the optimized condition. The data are presented as means of the standard deviations of triplicate assays. ${ }^{* * *} p<0.0001$. and $\mathrm{Zn}^{2+}$ ions inhibited lytic activity of LysSAP8. However, lytic activity of LysSAP8 treated with $1 \mathrm{mM}$ of calcium ions was found to be approximately $138 \%$, compared with the activity of the control. Furthermore, the activity of LysSAP8 was enhanced to $113 \%$ and $118 \%$ upon addition of solutions containing $1 \mathrm{mM} \mathrm{Co}^{2+}$ and $\mathrm{Mn}^{2+}$, respectively.

Consequently, its high efficacy of lysis can be achieved at $15-30^{\circ} \mathrm{C}$ in a buffer adjusted to $\mathrm{pH} 7-8$ and supplemented with $500 \mathrm{Mm} \mathrm{NaCl}$ and calcium ions. These results revealed that LysSAP33 had similar or better biochemical characteristics comparing with other staphylococcal endolysins, and might be a good candidate for use as a biocontrol agent [20,37]. Also, these optimized conditions suggest that the LysSAP8 might have good potential for applications in either food containing $\mathrm{NaCl}$ or neutral/subacid food.

\section{Antimicrobial Activity of LysSAP8 under the Optimized Condition}

Lytic activity of LysSAP8 under the optimized condition, as described in section 3.5 , was examined by the viable cell 
count (Fig. 7). When $1 \mu \mathrm{M}$ of LysSAP8 was inoculated, high antimicrobial activity against the target cells in their exponential phase of growth was observed after $30 \mathrm{~min}$, which resulted in a $\log$ reduction of approximately $3.46 \log (\mathrm{CFU} / \mathrm{ml})$. Compared to those of other staphylococcal endolysins, LysSAP8 demonstrated similar activity [19, 23]. However, LysSAP8 showed more rapid effects for reducing the target cells under the optimized condition. Especially, comparing with $\mathrm{P}-27 / \mathrm{HP}$ as one of the endolysins against S. aureus, LysSAP8 demonstrated tremendous capability as a biocontrol agent [42]. To reduce bacterial population, P$27 / \mathrm{HP}$ needs a minimum of $2 \mathrm{~h}$, but LysSAP8 showed similar activity in $30 \mathrm{~min}$ using a half of the concentration of P-27/HP. These results suggested that LysSAP8 could be an alternative candidate for use as a potent biocontrol agent demonstrating its activity with rapid effect.

\section{Acknowledgment}

This research was supported by high value-added food development project (117060-03-3-HD020) of the Korea Institute of Planning and Evaluation for Technology in Food, Agriculture and Forestry funded by the Ministry of Agriculture, Food and Rural Affairs.

\section{Conflict of Interest}

The authors have no financial conflict of interest to declare.

\section{References}

1. Knox J, Uhlemann AC, Lowy FD. 2015. Staphylococcus aureus infections: transmission within households and the community. Trends Microbiol. 23: 437-444.

2. Argudin MA, Mendoza MC, Rodicio MR. 2010. Food poisoning and Staphylococcus aureus enterotoxins. Toxins (Basel). 2: 1751-1773.

3. Choi SW, Lee JC, Kim J, Kim JE, Baek MJ, Park SY, et al. 2019. Prevalence and risk factors for positive nasal methicillin-resistant Staphylococcus aureus carriage among orthopedic patients in Korea. J. Clin. Med. 8(5): pii: E631.

4. Hennekinne J-A. 2018. Staphylococcus aureus as a Leading Cause of Foodborne Outbreaks Worldwide, pp. 129-146. In Fetsch A (ed.), Staphylococcus aureus, 1st Ed. Academic Press, Cambridge.

5. Hyeon JY. 2013. A foodborne outbreak of Staphylococcus aureus associated with fried chicken in Republic of Korea. J. Microbiol. Biotechnol. 23: 85-87.
6. Papadopoulos P, Papadopoulos T, Angelidis AS, Boukouvala E, Zdragas A, Papa A, et al. 2018. Prevalence of Staphylococcus aureus and of methicillin-resistant S. aureus (MRSA) along the production chain of dairy products in north-western Greece. Food Microbiol. 69: 43-50.

7. Lin DM, Koskella B, Lin HC. 2017. Phage therapy: An alternative to antibiotics in the age of multi-drug resistance. World J. Gastrointest Pharmacol. Ther. 8: 162-173.

8. Salmond GP, Fineran PC. 2015. A century of the phage: past, present and future. Nat. Rev. Microbiol. 13: 777-786.

9. Jamal M, Bukhari S, Andleeb S, Ali M, Raza S, Nawaz MA, et al. 2019. Bacteriophages: an overview of the control strategies against multiple bacterial infections in different fields. J. Basic Microbiol. 59: 123-133.

10. Wittebole X, De Roock S, Opal SM. 2014. A historical overview of bacteriophage therapy as an alternative to antibiotics for the treatment of bacterial pathogens. Virulence 5: 226-235.

11. Schmelcher M, Donovan DM, Loessner MJ. 2012. Bacteriophage endolysins as novel antimicrobials. Future Microbiol. 7: 1147-1171.

12. Schmelcher M, Loessner MJ. 2016. Bacteriophage endolysins: applications for food safety. Curr. Opin. Biotechnol. 37: 76-87.

13. Trudil D. 2015. Phage lytic enzymes: a history. Virol. Sin. 30: $26-32$.

14. Chang Y, Yoon H, Kang DH, Chang PS, Ryu S. 2017. Endolysin LysSA97 is synergistic with carvacrol in controlling Staphylococcus aureus in foods. Int. J. Food Microbiol. 244: 19-26.

15. Jasim HN, Hafidh RR, Abdulamir AS. 2018. Formation of therapeutic phage cocktail and endolysin to highly multidrug resistant Acinetobacter baumannii: in vitro and in vivo study. Iran J. Basic Med. Sci. 21: 1100-1108.

16. Zhang L, Li D, Li X, Hu L, Cheng M, Xia F, et al. 2016. LysGH15 kills Staphylococcus aureus without being affected by the humoral immune response or inducing inflammation. Sci. Rep. 6: 29344.

17. Gerstmans H, Rodriguez-Rubio L, Lavigne R, Briers Y. 2016. From endolysins to Artilysin(R)s: novel enzyme-based approaches to kill drug-resistant bacteria. Biochem. Soc. Trans. 44: 123-128.

18. Abaev I, Foster-Frey J, Korobova O, Shishkova N, Kiseleva N, Kopylov $\mathrm{P}$, et al. 2013. Staphylococcal phage 2638A endolysin is lytic for Staphylococcus aureus and harbors an inter-lyticdomain secondary translational start site. Appl. Microbiol. Biotechnol. 97: 3449-3456.

19. Fujiki J, Nakamura T, Furusawa T, Ohno H, Takahashi H, Kitana J, et al. 2018. Characterization of the lytic capability of a lysk-like endolysin, lys-phiSA012, derived from a polyvalent Staphylococcus aureus bacteriophage. Pharmaceuticals (Basel). 11(1). pii: E25.

20. Gu J, Xu W, Lei L, Huang J, Feng X, Sun C, et al. 2011. LysGH15, a novel bacteriophage lysin, protects a murine bacteremia model efficiently against lethal methicillin- 
resistant Staphylococcus aureus infection. J. Clin. Microbiol. 49: 111-117.

21. Haddad Kashani H, Schmelcher M, Sabzalipoor H, Seyed Hosseini E, Moniri R. 2018. Recombinant endolysins as potential therapeutics against antibiotic-resistant: current status of research and novel delivery strategies. Clin. Microbiol. Rev. 31: e00071-00017.

22. Sanz-Gaitero M, Keary R, Garcia-Doval C, Coffey A, van Raaij MJ. 2014. Crystal structure of the lytic CHAP(K) domain of the endolysin LysK from Staphylococcus aureus bacteriophage K. Virol J. 11: 133-133.

23. Melo LDR, Brandao A, Akturk E, Santos SB, Azeredo J. 2018. Characterization of a new Staphylococcus aureus kayvirus harboring a lysin active against biofilms. Viruses 10(4). pii: E182.

24. Kim NH, Park WB, Cho JE, Choi YJ, Choi SJ, Jun SY, et al. 2018. Effects of phage endolysin SAL200 combined with antibiotics on Staphylococcus aureus infection. Antimicrob. Agents Chemother. 62. pii: e00731-18.

25. Lu L, Cai L, Jiao N, Zhang R. 2017. Isolation and characterization of the first phage infecting ecologically important marine bacteria Erythrobacter. Virol J. 14(1): 104.

26. Bao H, Zhang P, Zhang H, Zhou Y, Zhang L, Wang R. 2015. bio-control of Salmonella Enteritidis in foods using bacteriophages. Viruses 7: 4836-4853.

27. Khan Shawan MM, Hasan MA, Hossain MM, Hasan MM, Parvin A, Akter S, et al. 2016. Genomics dataset on unclassified published organism (patent US 7547531). Data Brief. 9: 602-605.

28. Lowe TM, Eddy SR. 1997. tRNAscan-SE: a program for improved detection of transfer rna genes in genomic sequence. Nucleic Acids Res. 25: 955-964.

29. Altschul SF, Madden TL, Schäffer AA, Zhang J, Zhang Z, Miller W, et al. 1997. Gapped BLAST and PSI-BLAST: a new generation of protein database search programs. Nucleic Acids Res. 25: 3389-3402.

30. Larkin MA, Blackshields G, Brown NP, Chenna R, McGettigan PA, McWilliam H, et al. 2007. Clustal W and clustal X version 2.0. Bioinformatics 23: 2947-2948.

31. Kumar S, Nei M, Dudley J, Tamura K. 2008. MEGA: a biologist-centric software for evolutionary analysis of DNA and protein sequences. Brief Bioinform. 9: 299-306.

32. Cabrita LD, Bottomley SP. 2004. Protein expression and refolding - a practical guide to getting the most out of inclusion bodies, pp. 31-50. In El-Gewely MR (ed.), Biotechnology Annual Review Volume 10., 10 th Ed. Elsevier, Amsterdam.

33. Schmelcher $M$, Shen $Y$, Nelson DC, Eugster MR, Eichenseher F, Hanke DC, et al. 2015. Evolutionarily distinct bacteriophage endolysins featuring conserved peptidoglycan cleavage sites protect mice from MRSA infection. J. Antimicrob. Chemother. 70: 1453-1465.

34. Won G, Hajam IA, Lee JH. 2017. Improved lysis efficiency and immunogenicity of Salmonella ghosts mediated by coexpression of lambda phage holin-endolysin and X174 gene E. Sci. Rep. 7: 45139.

35. Larpin Y, Oechslin F, Moreillon P, Resch G, Entenza JM, Mancini S. 2018. In vitro characterization of PlyE146, a novel phage lysin that targets Gram-negative bacteria. PLoS One 13: e0192507.

36. Dong H, Zhu C, Chen J, Ye X, Huang YP. 2015. Antibacterial activity of Stenotrophomonas maltophilia endolysin P28 against both gram-positive and gram-negative bacteria. Front Microbiol. 6: 1299.

37. Chang Y, Kim M, Ryu S. 2017. Characterization of a novel endolysin LysSA11 and its utility as a potent biocontrol agent against Staphylococcus aureus on food and utensils. Food Microbiol. 68: 112-120.

38. Filatova LY, Donovan DM, Foster-Frey J, Pugachev VG, Dmitrieva NF, Chubar TA, et al. 2015. Bacteriophage phi11 lysin: physicochemical characterization and comparison with phage phi80alpha lysin. Enzyme Microb. Technol. 73-74: 51-58.

39. Becker SC, Dong S, Baker JR, Foster-Frey J, Pritchard DG, Donovan DM. 2009. LysK CHAP endopeptidase domain is required for lysis of live staphylococcal cells. FEMS Microbiol. Lett. 294: 52-60.

40. Gilmer DB, Schmitz JE, Euler CW, Fischetti VA. 2013. Novel bacteriophage lysin with broad lytic activity protects against mixed infection by Streptococcus pyogenes and methicillinresistant Staphylococcus aureus. Antimicrob. Agents Chemother. 57: 2743-2750.

41. Heselpoth RD, Yin Y, Moult J, Nelson DC. 2015. Increasing the stability of the bacteriophage endolysin PlyC using rationale-based FoldX computational modeling. Protein Eng. Des. Sel. 28: 85-92.

42. Gupta R, Prasad Y. 2011. P-27/HP endolysin as antibacterial agent for antibiotic resistant Staphylococcus aureus of human infections. Curr. Microbiol. 63: 39-45. 